\title{
PARQUE DO FLAMENGO: A CONSTRUÇÃO COTIDIANA DE UM ESPAÇO DEMOCRÁTICO*
}

LUCIA MARIA SÁ ANTUNES COSTA 


\section{RESUMO}

E ste trabalho discute a imagem pública do parque do Flamengo, no Rio de Janeiro, enquanto espaço democrático. Parque do Flamengo é um dos maiores e mais populares parques urbanos da cidade, atraindo uma população diversificada em termos de grupos sociais, atividades e intenções de uso. Baseando-se numa estratégia de pesquisa que combinou métodos qualitativos e quantitativos, este estudo enfoca o parque enquanto paisagem cultural, e portanto sujeita a diferentes forças e aos interesses de diferentes grupos ao longo do tempo. A imagem do parque como um "espaço democrático" será discutida através das experiências cotidianas que as pessoas têm do parque, com um enfoque em alguns usos que nem sempre tem um caráter de recreação ou lazer: a apropriação e a transformação do parque em espaço religioso, de trabal ho e de moradia; e a divisão social do parque. Este estudo mostra que a democratização do parque do Flamengo implica numa reinterpretação e reconstrução de sua paisagem pelos usuários, levando a uma segregação sócioespacial e inúmeros conflitos devido à multiplicidade de significados que são atribuídos ao parque. $O$ trabalho conclui argumentando que uma das maneiras de se lidar com esta diversidade de valores seria através de uma participação mais ativa da comunidade local na administração de espaços públicos.

\section{ABSTRACT}

\section{$T$}

his paper discusses the public image of parque do Flamengo, in Rio de Janeiro, as a democratic space. Parque do Flamengo is one of the city's largest and most popular urban parks, attracting a diversified population in terms of social groups, activities and intentions of use. This study, based on a research strategy which combined qualitative and quantitative methods, approaches the park as a cultural landscape, and therefore subject to different forces and to the interests of different groups along time. The image of the park as a "democratic space" will be discussed through people's daily experiences of the park, focusing on some uses which no necessarily have a character of recreation or leisure: the appropriation and transformation of the park in a religious and working space, in a space to live, and the social division of the park. This study reveals that the democratization of Parque do Flamengo implies in a reinterpretation and reconstruction of its landscape by the park users, leading to a socio-spatial segregation and a number of conflicts due to the multiplicity of meanings given to the park. The paper concludes arguing that one of the ways to deal with this diversity of values would be through a more active local community's participation in public spaces' administration. 


\section{INTRODUÇÃO}

P

arques públicos têm sido considerados "espaços democráticos" desde os primórdios de sua implantação nas cidades: áreas verdes urbanas de lazer disponíveis a todas as idades e grupos sociais indiscriminadamente, que todos podem usufruir em harmonia (Cranz, 1982, Conway, 1991). Mas a realidade da experiência cotidiana que as pessoas têm dos parques algumas vezes pode tanto questionar este mito dos parques enquanto espaços democráticos, como trazer uma interpretação diferente do que um espaço democrático venha a ser. Muitas vezes, o uso dos parques traz conflitos culturais e sociais que podem levar a uma segregação espacial de acordo com os diferentes grupos sociais. Linday (1977), por exemplo, apontou para alguns problemas gerados pelos usos conflitantes no Central Park em Nova York, em áreas usadas por diferentes grupos étnicos - usos que incluem música e dança, vendedores ilegais, jogo, tráfico de drogas e jantares ao ar livre. Mattews (1989) também menciona conflitos entre diferentes grupos de usuários em parques urbanos em Boston. Na verdade, cada parque tem suas singularidades em termos da democratização do seu espaço, que são local e culturalmente específicas.

Este trabalho discute a imagem pública do parque do Flamengo, no Rio de Janeiro, enquanto espaço democrático. Este tema é parte de uma pesquisa mais abrangente, dedicada ao estudo dos diversos valores e significados do parque, explorando três temas principais: o processo de criação do parque, as visões da comunidade local e do poder público em relação ao parque, e as diferentes experiências que as pessoas têm do parque (Costa, 1993). Através destes temas, o estudo revelou como uma pluralidade de valores e significados são construídos e negociados na criação e no uso de espaços públicos.

O parque do Flamengo é um parque à beira mar, criado nos anos 60 através de um espetacular aterro às margens da baia de Guanabara. Projetado como uma via-parque por uma equipe de profissionais de prestígio que incluía o arquiteto Affonso Eduar- 
do Reidy, o paisagista Roberto Burle Marx e o botânico Luiz Emygdio de Mello Filho, o parque é um dos mais significativos exemplos de intervenções paisagísticas no Rio de Janeiro (Motta, 1984, Costa, 1993). Com 120 hectares, o parque do Flamengo é também um dos maiores e mais populares parques urbanos da cidade. A variedade de atividades que oferece, juntamente com sua excelente localização e seu fácil acesso por meio de transporte público, faz com que o parque do Flamengo seja intensamente usado não só por moradores locais, mas também por moradores de partes longínquas da cidade.

Este estudo busca trazer uma contribuição à literatura, que aborda parques urbanos enquanto paisagens culturais, e portanto sujeitas à diferentes forças e aos interesses de diferentes grupos ao longo do tempo (Cranz, 1982, Burgess et al 1988, Jackson, 1989). Parque do Flamengo nos revela com muita clareza como as pessoas constróem suas próprias paisagens, reinterpretando e recriando diversas áreas através de suas experiências cotidianas do parque, que são norteadas pelas diferentes maneiras de se ver o mesmo espaço urbano.

Como o objetivo geral da pesquisa foi o de investigar valores, significados e usos do parque do Flamengo, a estratégia de pesquisa combinou métodos qualitativos e quantitativos. A pesquisa de campo envolveu entrevistas informais, observação participante, questionários, observações de comportamento e pesquisas em arquivos e bibliotecas. Esta metodologia diversificada permitiu uma melhor compreensão da multiplicidade de valores e significados que os moradores das cidades atribuem a seus parques públicos.

\section{UM ESPAÇO DEMOCRÁTICO}

A imagem do parque do Flamengo como um 'espaço democrático' foi uma das descrições mais comuns usadas tanto por usuários quanto por funcionários para se referirem ao parque. $\mathrm{O}$ fato de ser um espaço aberto a todas as idades e grupos sociais era considerado um aspecto muito positivo da área. A frase "... 
todo mundo vem, do mendigo ao intelectual!..." era uma constante nas conversas sobre o dia-a dia do parque. A imprensa também tem reforçado a construção desta imagem, referindo-se ao parque do Flamengo como uma "festa democrática" ou mesmo o "paraíso democrático" do Rio. Na verdade, o parque é visitado por uma população extremamente diversificada em termos de grupos sociais, atividades e intenções de uso. Mas a imagem de um espaço democrático contrasta com as realidades das experiências cotidianas que as pessoas têm do parque. Os diferentes grupos não necessariamente compartilham dos mesmos códigos de comportamento social ou dos mesmos valores sociais e culturais. Além disso, o parque do Flamengo não tem um constante controle social eficiente, tais como regras expostas ou a presença de guardas ou vigilantes que possam estabelecer um sistema comum de regras de comportamento e de valores. Esta situação diversificada gera conflitos e tensões as quais, até um certo ponto, são resolvidas através de uma segregação espacial do parque. Todos os diversos grupos dividem o mesmo parque, porém, não necessariamente no mesmo lugar ou na mesma hora. De modo que todos possam igualmente a usar o parque, o uso é silenciosamente negociado entre os usuários não apenas em termos de atividades, mas também em termos de grupos sociais. Esta mistura social, ou a "democratização" do parque, é conseguida através da negociação do espaço e da observação de certos códigos de comportamento. Shields (1991, p. 7) usa o termo sócioespacialização para se referir à "construção social do espacial que é a formação de elementos, práticas e processos tanto discursivos quanto não discursivos". Este trabalho pretende mostrar, então, como o caráter democrático do parque do Flamengo implica numa sócioespacialização de sua paisagem, que é cultural e socialmente construída. Para isto, serão abordados alguns dos diversos usos do parque, que nem sempre ou necessariamente têm um caráter de recreação e lazer, e que são importantes para revelar as tensões geradas pelas diferentes experiências cotidianas do parque por diferentes grupos sociais. 


\section{O PARQUE ENQUANTO ESPAÇO RELIGIOSO}

O parque do Flamengo tem sido usado como espaço para diversas atividades religiosas, que variam em caráter e em escala. Já um dos primeiros usos da área, quando era ainda um aterro, foi para celebrações religiosas da igreja católica: o XXXIII Congresso Eucarístico Internacional em 1955. Em 1980, parque do Flamengo foi novamente escolhido como o lugar para a missa ao ar livre, celebrada pelo Papa João Paulo II durante sua visita oficial ao Rio. A escolha do lugar, entretanto, não pareceu estar relacionada a nenhum significado religioso em particular que $o$ parque possa ter para a igreja católica. Ao contrário, o parque foi escolhido pelo seu caráter de lugar privilegiado da cidade para espetáculos ao ar livre, não só revelando uma paisagem de grande beleza, como também capaz de acolher uma enorme multidão de pessoas para uma cerimônia religiosa de tamanha importância. Numa escala diferente, outros grupos religiosos, principalmente as igrejas evangélicas, também procuram o parque do Flamengo aos domingos para rezar, ler a bíblia e cantar hinos religiosos. Mais uma vez, o parque não parece ter nenhum significado religioso especial para estas pessoas. $\mathrm{Na}$ verdade, o parque do Flamengo atrai estes grupos não porque tenha natureza, mas porque tem gente.

Entretanto, para outros grupos o parque realmente contém atributos que dão a ele um significado religioso. Estes atributos estão diretamente ligados à predominante presença da natureza. Parque do Flamengo é intensamente usado e apropriado como um lugar para atividades religiosas pelos praticantes de alguns cultos afro-brasileiros, tais como umbanda, macumba ou candomblé, cujas divindades são espíritos da natureza, e portanto associados à floresta e seus elementos (Bastide, 1971). Desta forma velas, flores, alimentos e outras oferendas religiosas proliferam pelas árvores, pedras e clareiras do parque. Parque do Flamengo é então transformado em um lugar onde a natureza é celebrada de um modo religioso. Além das oferendas indivi- 
duais, celebrações coletivas como a Festa de Yemanjá na passagem do Ano Novo atraem grandes grupos de pessoas ao longo da praia.

Estes rituais são parte da cultura urbana no Rio, acontecendo em várias matas, florestas e praias da cidade. Mas o parque do Flamengo é o único parque em que isto acontece, porque todos os outros são gradeados e seus portões fechados ao cair da noite. No que diz respeito à administração do parque, estas práticas religiosas representam um grande problema. As velas, além do risco de incêndio, causam grandes estragos nos troncos das árvores, o que implica num permanente e oneroso trabalho de recuperação. Além disso, estas oferendas religiosas que se espalham por todo o parque são consideradas "lixo" e removidas todas as manhãs pelo pessoal da limpeza. Entretanto, a remoção destas oferendas algumas vezes representa um conflito para alguns funcionários. Alguns deles reconhecem e respeitam o significado religioso destas oferendas e se recusam tanto a tocá-las quanto a removê-las, temendo ofender a divindade a quem a oferenda foi dedicada. Estas atividades religiosas no parque do Flamengo representam um dos mais delicados conflitos em termos de uso e significado do parque. Nunca houve, entretanto, nenhuma tentativa de se chegar a um acordo entre estes grupos religiosos e a administração do parque.

\section{O PARQUE COMO UM LUGAR DE TRABALHO}

Para muitas pessoas, o parque do Flamengo representa uma estratégia de sobrevivência para enfrentar o desemprego ou baixos salários. Para eles, o parque é um lugar de trabalho onde eles podem superar a falta de oportunidade no mercado formal através do exercício de uma grande dose de imaginação e criatividade. Pescadores, catadores de mariscos, de papel e vendedores ambulantes compõem o universo dos que ganham a vida no parque. Na verdade, isto não acontece apenas no parque do Flamengo. Nos últimos anos, vários espaços públicos 
livres da cidade, tais como praças e ruas principais de comércio, foram ocupados por um imenso número de vendedores de rua.

Enquanto a pescaria no parque do Flamengo é para uns uma recreação de fim-de-semana, para outros é um modo de ganhar a vida, vendendo sua produção nos mercados e restaurantes. Esta atividade não é licenciada e, portanto, considerada ilegal. Apesar disto, a pesca é geralmente aceita e este grupo não incomoda nem outros usuários, nem a administração do parque. Isto em parte é devido ao fato deles serem poucos em número, e também porque o território dos pescadores não interfere nas outras atividades do parque.

Entretanto, o número de pescadores é pequeno quando comparado às centenas de pessoas que usam o parque para vender todo o tipo de comida e objetos, principalmente nos fins-de-semana. Poucos deles têm licença e a grande maioria é considerada ilegal. Mais uma vez esta atividade não é, de um modo geral, controlada pelo poder público. Os vendedores ambulantes colocam suas barracas onde querem e vendem o que querem, sem nenhuma regulamentação. A negociação do espaço do parque é feita entre os próprios vendedores, e alguns têm pontos estabelecidos no parque há muitos anos. A maioria se concentra na área central do parque ao longo da praia e ao redor dos campos de futebol, áreas de maior concentração de usuários.

Na percepção de muitos usuários e funcionários do parque, os ambulantes são considerados numerosos e suas atividades vistas como predatórias, pois são criticados por deixarem uma quantidade enorme de lixo e acusados de estragarem os gramados e as árvores. Além disso, os ambulantes são acusados de colocar a saúde da população em risco vendendo comida sem qualidade ou controle de higiene. E finalmente, os ambulantes são também acusados de estragarem a beleza do parque na sua ocupação caótica e desordenada do espaço. A polícia, por sua vez, reclama que os ambulantes ilegais disfarçam o tráfico de drogas no parque do Flamengo. Entretanto, as várias instâncias admi- 
nistrativas que se superpõem no parque se esquivam mutuamente de suas responsabilidades para enfrentar estas questões.

Por outro lado, muitos outros usuários são favoráveis à presença deste ambulantes, pois eles suprem uma demanda que não foi considerada no projeto original do parque. A área central do parque do Flamengo, ao longo dos $4 \mathrm{~km}$ de praia, justamente a que atrai um maior número de pessoas, não possui nenhum restaurante ou bar onde os freqüentadores possam comprar comida ou bebida. O parque tem apenas dois restaurantes, um em cada extremo de sua área. Os vendedores ambulantes, portanto, ocupam um espaço que foi deixado livre, em termos de projeto e em termos de controle, e suprem uma demanda dos usuários do parque. Além disso, muitos vendedores, principalmente aqueles que têm barraquinhas estabelecidas no parque durante toda a semana, cumprem um papel informal porém bastante importante no que diz respeito à segurança do parque do Flamengo. Para muitos freqüentadores, os vendedores ambulantes mantêm um olhar protetor em relação às mães com crianças pequenas ou pessoas sozinhas. A presença de vendedores ambulantes como um meio de reduzir crime e vandalismo em espaços públicos foi também reconhecida por Ewing e Wallis (1979). Discutindo estratégias para prevenção de crime em espaços livres, eles argumentam que 'atividades de apoio', tais como vendedores ambulantes podem aumentar o uso e criar uma condição de vigilância natural.

Whyte (1980) já notou como vendedores ambulantes de alimentos são importantes para a popularidade e sociabilidade de muitos espaços públicos nos EUA. No parque do Flamengo, os vendedores ambulantes de alimentos e bebidas são tanto causa como conseqüência do grande número de pessoas que afluem para o parque nos fins-de-semana. Alguns destes vendedores trazem cadeiras móveis, mesas, e de fato redesenham a paisagem do parque criando mini-bares ao longo da beira-mar. Aos domingos, estes lugares são geralmente cheios de vida, com música, pessoas dançando, comendo, bebendo, conversando verdadeiras pequenas festas ao ar livre. $\mathrm{Na}$ verdade, estes 
vendedores ambulantes cumprem uma importante função no parque do Flamengo, e os órgãos públicos poderiam enfrentar esta questão com outras estratégias que não a de simplesmente retirá-los do parque de tempos em tempos.

\section{O PARQUE COMO UM LUGAR DE MORADIA}

Mendigos e pessoas sem casa têm sido usuários tradicionais do parque do Flamengo desde que a área era ainda um aterro. Muitos residentes locais se referiram a este antigo uso da área aterrada, e a imprensa também vem documentando sua presença desde os primeiros anos do parque.

Esta situação não mudou muito ao longo dos anos. Atualmente, para mendigos e pessoas sem casa o parque do Flamengo é o lugar onde acontecem todos os aspectos de suas vidas cotidianas, tanto no âmbito público quanto privado. O parque é o lugar onde eles preparam suas refeições, comem, tomam banho, lavam suas roupas, dormem e eventualmente ganham seu dinheiro - tanto através da mendicância como trabalhando em atividades informais tais como catando papel ou marisco. De acordo com a Fundação Leão XIII, que era o órgão estadual à época encarregado da população de rua do Rio, em média $60 \%$ são homens. Muitos são alcoólatras ou pessoas com doenças mentais, e homossexuais que ganham a vida se prostituindo no parque. Eles são vistos no parque em grupos, ou adultos sozinhos, ou algumas vezes famílias com crianças.

Esta dramática situação no parque do Flamengo é, na verdade, um reflexo de um problema da cidade como um todo. Embora mendigos e pessoas sem casa se espalhem cada vez mais por um grande número de praças e ruas da cidade, o parque do Flamengoé o único parque em que eles moram porque é o único parque aberto à noite. Desde as primeiras pressões feitas pela Associação dos Moradores do Flamengo no fim de 1989, a Fundação Leão XIII passou a remover regularmente do parque do Flamengo mendigos e pessoas sem casa, eventualmente duas 
vezes por semana. Em média, o número de pessoas removidas do parque variava entre 20 a 60 por vez.

Como a maioria dos outros usuários, os mendigos e pessoas sem casa também têm seus territórios estabelecidos no parque. Embora seu número possa flutuar de acordo com as atuações periódicas do poder público e da comunidade, os lugares são quase sempre os mesmos. Algumas vezes duas ou três pessoas estão ocupando um lugar que antes era ocupado por duas ou três famílias. Há uma tendência, entretanto, dos mendigos e pessoas sem casa se esconderem dos outros usuários do parque. Seus territórios são normalmente aqueles não usados freqüentemente por outras pessoas, ou áreas densamente arborizadas, e algumas vezes debaixo de passarelas ou viadutos. Estas áreas, que para outros usuários do parque significam perigo ou ameaça, para estes grupos significam proteção e segurança, lugares onde dificilmente serão vistos ou incomodados.

A presença de mendigos e pessoas morando no parque é considerada um problema sério para os funcionários e muitos usuários e não usuários do parque. Primeiramente, eles são uma fonte de medo e insegurança. Este medo vem do fato de que as pessoas não são mais capazes de identificar visualmente aqueles que são realmente mendigos daqueles que se disfarçam como tal com o intuito de praticar pequenos roubos.

Segundo, o comportamento dos mendigos e pessoas que moram no parque segue um padrão completamente diferente do comportamento dos demais usuários. De um modo geral, para os demais usuários eles têm uma imagem ligada a vandalismo e sujeira. Mas em termos de seu comportamento, o que mais incomoda e constrange outros usuários é quando mendigos e moradores do parque fazem sexo ao ar livre, não importando se é dia ou noite ou se tem alguém passando. Este comportamento é considerado extremamente ofensivo e inaceitável, e simboliza para os freqüentadores e moradores locais uma total ausência do poder público na área. Uma das maneiras em que outros usuários do parque contornam esta situação é evitar as áreas do 
parque em que tais grupos possam ser encontrados. O território deles é geralmente bem conhecido. Outra maneira que a comunidade local enfrenta esta questão é pressionando fortemente os órgãos públicos para remover tais grupos do parque.

Apesar da reclamação geral quanto à presença de mendigos e pessoas sem casa, para alguns usuários do parque eles não são percebidos como um problema desde que sejam poucos em número. Neste caso este grupo é quase invisível e portanto tolerado. Mas o "caráter democrático" do parque é mais uma vez dependente do seu grande tamanho, que ajuda a minimizar conflitos, como diz um morador local: "o parque é muito grande, eles não aparecem..."

Talvez um dos grandes problemas da presença de mendigos e pessoas sem casa no parque do Flamengo não é simplesmente a ameaça ou o perigo que este grupo possa representar, ou os conflitos ligados a um comportamento social que eles possam trazer. Este grupo é também a própria antítese da imagem do parque como uma festa - um espaço feliz. Mendigos e pessoas sem casa não apenas simbolizam, mas são a expressão viva da tristeza, da pobreza, da miséria e da falta de esperança de um grupo largado à margem pela sociedade. Este é um drama social difícil de se conviver, principalmente num parque público, um dos espaços livres urbanos por excelência com uma imagem ligada à ludicidade e ao prazer.

\section{TENSÕES ENTRE MORADORES LOCAIS E "OS OUTROS"}

Para muitos residentes locais, o parque é dividido em duas áreas sociais distintas em termos de uso. O lado esquerdo da praia e seus arredores - em frente aos bairros Glória e Centro - é visto como sendo usado principalmente por suburbanos de baixa renda e, numa área menor, por travestis e homossexuais. $O$ outro lado da praia, em frente ao bairro do Flamengo, é considerado o "lado elite freqüentado por residentes locais de classe média", expressão esta muito usada no discurso dos 
moradores dos bairros próximos sobre o parque. O lado esquerdo do parque é evitado por um grande número de residentes locais de classe média por não ser considerado um "local de família"

No Rio, são chamados pejorativamente "suburbanos" aqueles que moram nas periferias da cidade, normalmente áreas de baixa renda. Estas pessoas são o segundo grupo de usuários do parque do Flamengo em termos de local de residência. Os resultados dos questionários sugerem que pessoas que moram longe do parque tendem a ficar do lado esquerdo do parque, enquanto residentes locais tendem a ficar principalmente do lado oposto. Entretanto, não é apenas o local de residência que define um "suburbano" no Rio, mas também, e talvez mais fortemente, todo um conjunto de modos de comportamento. No Rio como em vários outros lugares, classes sociais são também diferenciadas por certos padrões de vestuário, gestos, comportamentos e atitudes que ajudam a construir e a estabelecer uma hierarquia social (Da Matta, 1978). Neste sentido, muitos usuários do parque, que não necessariamente moram nos subúrbios distantes, são 'rotulados' pelos residentes locais de classe média como "suburbanos" - não apenas pelo seus locais de residência, mas principalmente pela sua aparência e comportamento.

Shields (1991, p. 47) argumenta que "a maneira pela qual a espacialização é mais visível é nas práticas espaciais e nas conotações que as pessoas associam com os lugares... na conversa de todo dia" De fato, quando conversando sobre a "área suburbana" do parque do Flamengo, as pessoas deixavam claro que os usuários não apenas eram diferentes na aparência, como também agiam diferentemente:

"... você sente que é diferente... todos são usuários, mas o comportamento é o que define a área (...) lá eles fazem churrasco, fazem roda de samba, fazem uma porção de coisas que não combina com o outro pedaço da praia, né, que não tem isso." (morador do Flamengo) 
Usuários desta parte do parque expressaram uma grande variedade de razões para sua escolha. As principais motivações são os equipamentos da área que têm um forte apelo popular, tais como os campos de futebol e a praia. A praia é percebida como sendo mais limpa por não ter nenhuma saída de esgoto por perto. Outros também colocaram que aquele lugar era o mais perto da primeira parada de ônibus vindo da zona norte do Rio. Além disso, muitas pessoas também disseram que freqüentam a área porque seus amigos e círculo social também freqüentam.

Para muitos moradores locais, entretanto, os suburbanos são considerados como pessoas "de fora", que não compartilham dos padrões de comportamento da "classe média", e que portanto, são consideradas "mal-educadas", fazendo um uso "predatório" do parque. Além disso, problemas de vandalismo e lixo são geralmente atribuídos, junto com os vendedores ambulantes e os mendigos, ao usuário considerado "de fora":

"... no verão o parque recebe, no fim-de-semana, uma média de 300 mil pessoas de fora. E estas pessoas destróem. Elas não estão preparadas para usar um parque como o do Flamengo. Quando acaba o sábado e o domingo, se você for ao parque você chora de tristeza... é um quadro triste." (morador do Flamengo)

Para alguns residentes locais estes conflitos relacionados a comportamento e valores sociais são expressões de sentimentos de propriedade sobre o parque, e são resolvidos através de uma segregação social do espaço. Para outros a presença de usuários de baixa renda é vista com um preconceito ainda maior. Para alguns o parque tem a imagem de ser um lugar freqüentado predominantemente por suburbanos e esta é uma das razões para, definitivamente, não ir ao parque do Flamengo. Neste sentido, estas pessoas deixam claro que não freqüentam o parque do Flamengo porque não querem se identificar com um lugar considerado como 'parque de suburbanos'

outro grupo que usa o lado esquerdo do parque é o dos travestis e homossexuais. Alguns estudos já abordaram a expres- 
são espacial da comunidade gay e como esta pode definir o caráter social de uma determinada paisagem (Bell, 1991 e Jackson, 1989 para uma crítica ao estudo de 'espaços gay'). No parque do Flamengo, este grupo se concentra principalmente junto às pedras, bem no final da praia perto da Marina da Glória. Esta parte do parque tem sido apropriada por travestis e homossexuais há muito tempo. A imprensa vem noticiando a presença deste grupo no parque desde o início dos anos 70, se referindo àquela parte do parque como 'ninho das cobras' Esta parte do parque do Flamengo é ainda hoje considerada um lugar perigoso, e também conhecida como uma área de prostituição masculina, principalmente à noite. Com escreve Jackson (1989, p.121) "gays podem ser percebidos como uma ameaça... em lugares onde eles estão mais concentrados e socialmente visíveis" A área é muito evitada e discriminada tanto em termos de sexualidade como em termos de classe social.

A presença deste grupo não é bem aceita por outros moradores porque seu comportamento é considerado indecente e imoral. Muitos residentes locais pararam de freqüentar esta área depois de ver homossexuais terem relações sexuais em plena luz do dia. Além disso muitas pessoas, principalmente homens jovens, reclamam de assédio sexual. Entretanto, para outros moradores locais os homossexuais não representam nenhuma ameaça ou problema, já que o parque é considerado grande o suficiente para receber diferentes grupos. Eles são vistos, nas palavras de Jackson (1989) como "uma minoria socialmente insignificante e invisível". Como diz um morador do bairro do Flamengo: "o parque é muito grande, tém lugar prá todos..."

Entretanto, o parque é para todos desde que cada grupo fique em seu próprio território. Esta área do parque do Flamengo é na verdade extremamente complexa em termos de diferentes usos. Estes também incluem a Marina da Glória, freqüentada principalmente por uma população abonada que pode manter e usufruir barcos e iates, e as instalações de diversos órgãos públicos que atuam no parque. Nestes casos, os conflitos foram parcialmente resolvidos através da segregação do espaço por meio 
de barreiras físicas, claramente demarcando o domínio de cada área. A Marina da Glória é fechada com grades de ferro e tem guardas na entrada. Estas barreiras são, na verdade, apenas simbólicas, pois a Marina é pública e o acesso é livre a todos, mas as grades de fato inibem o acesso. Usuários da Marina aparentam ser, de um modo geral, bastante favoráveis a estas barreiras físicas, se referindo freqüentemente ao comportamento 'não civilizado' dos travestis, gays e dos suburbanos, deixando claro diferenças sociais e culturais.

A área administrativa do parque é cercada por muros altos com seguranças na entrada, e portanto, não está aparentemente integrada no projeto do parque como um todo. Funcionários do parque defendem a necessidade destes muros, argumentando que toda a área ajardinada atrás destas construções, inclusive as passarelas, são extremamente perigosas.

Desta forma, a democratização do espaço do parque para moradores locais implica que grupos "de fora", tais como os suburbanos e os travestis, fiquem tanto quanto possivel dentro das suas fronteiras culturais e sociais invisíveis no parque. Mas para os funcionários do parque e usuários da Marina, a democratização do espaço requer medidas mais radicais: um limite físico diferenciando os territórios e recortando a paisagem. Parque do Flamengo é então redesenhado e reconstruído em resposta a conflitos sociais e culturais, pois nenhuma destas barreiras físicas foram previstas no projeto original.

\section{CONSIDERAÇÕES FINAIS}

Este trabalho procurou mostrar que a "democratização" do parque do Flamengo é uma construção social que se faz através de uma negociação complexa de interesses diversos, parte de um processo dinâmico que envolve relações culturais e sociais no espaço e no tempo. Áreas do parque são apropriadas por diferentes grupos e esta apropriação, algumas vezes, implica numa transformação da paisagem, seja em caráter ou em forma. Assim, a paisagem é renegociada, reinterpretada e recriada de 
acordo com os valores dos diferentes grupos que reivindicam seus territórios no parque.

Parque do Flamengo nos revela, através destas diversas experiências, uma importante característica de muitos outros parques urbanos em diversas localidades: a enorme variedade de grupos sociais que os parques atraem, e os conflitos a respeito de comportamento, uso, valores e significados que esta pluralidade de interesses traz. Por esta razão, problemas sociais se materializam e se tornam visíveis em parques públicos e espaços livres com mais intensidade do que em qualquer outro espaço urbano. Carry and Lynch (1981) chegam a comparar espaços livres públicos a verdadeiros campos de batalha, devido aos conflitos gerados por diferentes experiências e expectativas. Como conseqüência, de um modo geral, estas questões têm sido abordadas pelo poder público como problemas dos parques, e não como problemas sociais. Nos EUA, por exemplo, o poder público muitas vezes enfrenta esta questão simplesmente vendendo ou fechando espaços verdes públicos que são considerados não lucrativos (Heckscher, 1981) ou não administráveis sob o ponto de vista social.

A questão principal, e também a mais difícil, é a de como encontrar as melhores maneiras de lidar com a grande variedade de grupos sociais, que são atraídos aos parques públicos. Esta pesquisa mostrou que podem haver outras maneiras de lidar com tal diversidade de grupos sociais e de interesses (Costa, 1993). Uma das mais efetivas é quando a comunidade local ativamente participa e se envolve nas realidades cotidianas do parque - seja colaborando na fiscalização e controle do parque, seja organizando as atividades culturais e sociais que mais se encaixem nos seus interesses. Deve haver uma responsabilidade dividida entre o poder público, os administradores do parque e a comunidade. Entretanto, a melhor dinâmica para esta gestão certamente irá variar de acordo com os diferentes lugares e culturas. Algumas tentativas de sucesso têm sido feitas, como nos Augarten Gardens em Viena, Central Park em Nova York e no Birkenhead Park na Inglaterra (Costa, 1993). Mas mesmo 
quando esta administração conjunta não acontece, como é o caso do parque do Flamengo, a força da dedicação da comunidade para com o parque se mostrou um instrumento poderoso em manter a vitalidade do parque apesar de todos os problemas e conflitos que surgem devido a enorme variedade de grupos sociais usando a área.

A imagem pública do parque do Flamengo como um "espaço democrático" simboliza uma aspiração de uma sociedade ideal - o sonho de um lugar que pode ser compartilhado e usufruído em harmonia por muitos grupos sociais. Na verdade, parque do Flamengo se apresenta como um imenso palco onde os múltiplos aspectos da realidade social e cultural da cidade se espelham, e onde conflitos sobre múltiplos usos, significados e valores são contestados e negociados pelos diferentes grupos sociais. Neste sentido, o parque do Flamengo é um dos mais significativos símbolos urbanos do Rio, pois ele claramente revela tanto aspectos do caráter tão particular da cidade - em termos estéticos, políticos, culturais e sociais.

\section{BIBLIOGRAFIA}

BASTIDE, R. As religiōes africanas no Brasil: Contribuição a uma sociologia das interprenetraçōes das civilizações. Il vol. São Paulo: Livraria Pioneira Editora. 1971.

BELL, D. J. Insignificant others: lesbian and gay geographies. Area, n. 23, v. 4, p. 323-329. 1991.

BURGESS, J., HARRISON, C. M., LIMB, M. People, parks and the urban green: a study of popular meanings and values for open spaces in the city. Urban Studies, n. 25, p. 455-473. 1988.

CRANZ, G. The politics of park design: a story of urban parks in America. Cambridge: Mass.: MIT Press. 1982.

CARR, S., LYNCH, K. Open space: freedom and control. In: TAYLOR, L. (ed). Urban open spaces. London: Academy Editions, 1981, p. 17-18. 
CONWAY, H. People's park: the design and development of Victorian Parks in England. Cambridge: Cambridge University Press. 1991.

COSTA, L. M. S. A. Popular values for urban parks: a case study of the changing meanings of parque do Flamengo in Rio de Janeiro. Thesis (Ph. D.) - University College. Londres, Inglaterra, 1993.

DA MATTA, R. Carnavais, malandros e herbis: para uma sociologia do dilema brasileiro. Rio de Janeiro: Zahar Editores, 1978.

EWING, B. G., WALLIS, A. Crime and vandalism. In: TAYLOR, L. (ed) Urban open spaces. New York: The Smithsonian Institution. 1981, London: Academy Editions, p. 104-105.

HECKSCHER, A. The management of open spaces. In: Taylor, L. (ed) Urban open spaces. London: Academy Editions, 1981, p. 19-20.

JACKSON, P. Maps of meaning. London: Unwin Hyman, 1989.

LINDAY, N. Drawing Socio-Economic Lines in Central Park: An Analysis of New York's Cultural Clashes. Landscape Architecture, n. 67, p. 515-520. 1977.

MATTHEWS, R. Polishing up the necklace. Landscape Design, n. 180, p. 19-22. 1989.

MOTTA, F Roberto Burle Marx e a nova visão da paisagem. São Paulo: Nobel, 1984.

SHIELDS, R. Places on the margin: Alternativegeographies of modernity. London: Routledge, 1991.

WHYTE, W. H. The social life of small urban spaces. Washington, D. C.: The Conservation Foundation, 1980.

(*) Trabalho apresentado no Seminário Interdisciplinar ANPUR Cidade e Produção do Cotidiano, realizado em Recife, novembro 1993. 